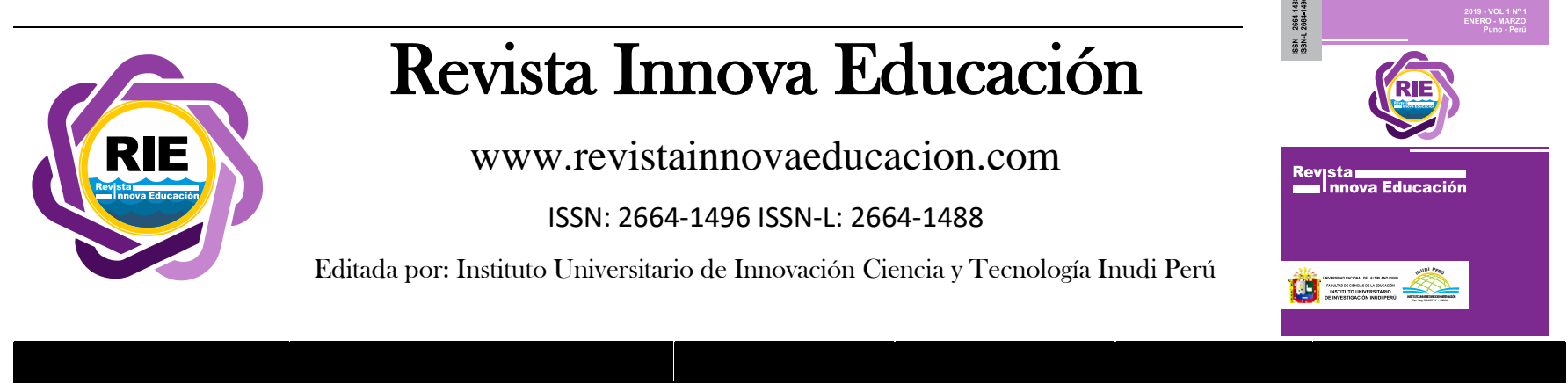

\title{
Aplicación del enfoque cognitivo, comunicativo y sociocultural en la comprensión de textos literarios en estudiantes de secundaria
}

\author{
Application of the cognitive, communicative and sociocultural approach in the comprehension of \\ literary texts in high school students \\ Mario Tinta \\ DOI: https://doi.org/10.35622/j.rie.2019.01.011
}

Universidad Nacional del Altiplano; email: mariotinta12345@gmail.com

Recibido el 15/01/2019/ Aceptado el 27/01/2019

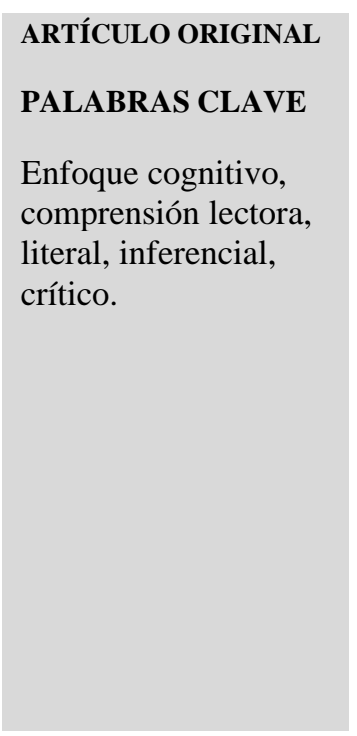

\begin{abstract}
La investigación planteó como objetivo: determinar la eficacia del enfoque cognitivo, comunicativo y sociocultural en la comprensión de textos literarios en estudiantes del segundo grado de secundaria de la Institución Educativa Secundaria Independencia Nacional, Puno, 2018. Según el paradigma predominante, la investigación fue cuantitativa. En cuanto a la estrategia de aplicación fue experimental. El diseño que se utilizó en la investigación fue cuasi - experimental, con dos grupos. Se aplicó el tratamiento al grupo experimental. La población estuvo conformada por 156 estudiantes. La muestra estuvo conformada por 64 estudiantes. La técnica que se utilizó fue la evaluación o medición. El instrumento que se utilizó fue la prueba escrita. Se arribó a la siguiente conclusión: el enfoque cognitivo, comunicativo y sociocultural es eficaz en la comprensión de textos literarios en los estudiantes. Se llega a esta conclusión porque la $\mathrm{Z}$ calculada es superior a la $\mathrm{Z}$ tabla: $|15,58|>|1,96|$, por lo que se confirma la hipótesis alterna. Asimismo, en la prueba de salida los estudiantes predominantemente se ubican en la escala "Logro Previsto" con 16 estudiantes (50\%), mientras que en la prueba de entrada predominaba la escala "En Inicio" con 17 estudiantes (53\%). El promedio de la prueba de entrada fue de 7,19 y el de la prueba de salida fue 17.03 .
\end{abstract}

\section{KEYWORDS}

Cognitive focus, reading comprehension, literal, inferential, critical.

\begin{abstract}
The objective of the research was to determine the effectiveness of the cognitive, communicative and sociocultural approach in the comprehension of literary texts in secondary school students of the National Independence Secondary Education Institution, Puno, 2018. According to the predominant paradigm, the research was quantitative. Regarding the application strategy, it was experimental. The design used in the research was quasi - experimental, with two groups. The treatment was applied to the experimental group. The population consisted of 156 students. The sample consisted of 64 students. The technique that was used was the evaluation or measurement. The instrument that was used was the written test. The following conclusion was reached: The cognitive, communicative and sociocultural approach is effective in the comprehension of literary texts in the students. This conclusion is reached because the calculated $Z$ is superior to the $Z$ table: $|15,58|>|1,96|$, so the
\end{abstract}


alternative hypothesis is confirmed. Likewise, in the exit test the students are predominantly located on the "Achieved Achievement" scale with 16 students (50\%), while in the entrance test the "On Start" scale predominated with 17 students (53\%).

The average of the entrance test was 7.19 and that of the exit test was 17.03.

\section{INTRODUCCIÓN}

En la investigación se abordan aspectos relativos a la comprensión de textos y a la propuesta de aplicación del enfoque cognitivo, comunicativo y sociocultural para consolidar capacidades de comprensión de textos. Uno de los pilares de la educación peruana es que los estudiantes del nivel secundario desarrollen lecturas comprensivas. Más aún si existen situaciones alarmantes en resultados internacionales en este tópico. Por ello, dentro del proyecto PISA se entiende la competencia lectora como la capacidad individual para comprender, utilizar y analizar textos escritos con el fin de lograr sus objetivos personales, desarrollar sus conocimientos y posibilidades y participar plenamente en la sociedad (Caño \& Luna, 2015).

Según la evaluación PISA en comprensión lectora, si bien hubo un incremento en el puntaje del 2015 en relación con el puntaje del 2000, seguimos siendo uno de los países con deficiencia en el desarrollo de las competencias en comprensión lectora. Estos resultados confirman el deficiente nivel de los estudiantes en comprensión lectora en sus niveles literal, inferencial y crítico. Ello significa que no se aplican políticas eficaces a fin de revertir esta situación, porque desde el año 2000 no hubo evolución positiva.

Por otra parte, en la Región Puno, la situación es similar porque de acuerdo con los resultados de la Evaluación Censal de Estudiantes (ECE), en comprensión lectora en el 2016 la Región Puno en comprensión lectora, se ubicó en lugar 12 a nivel nacional. Lo que significa que sólo el 25,2\% comprende adecuadamente un texto; mientras que el 74,8\% tiene problemas de comprensión lectora. De igual modo se nota la ausencia de conocimientos y aplicación acertada de enfoques productivos en comprensión de textos como el enfoque sociocultural, funcional, comunicativo y cognitivo, dejando de lado muchas veces las estrategias que los caracterizan. Esto se refleja en la falta de criterios y técnicas de estudio implementadas por los propios docentes en la tarea de enseñanza.

Por todas las razones expuestas, se presentan las siguientes interrogantes de investigación: ¿En qué medida es eficaz la aplicación del enfoque cognitivo, comunicativo y sociocultural para elevar la comprensión de textos literarios en estudiantes de secundaria? ¿Cuál es el nivel de recuperación de información (nivel literal) que muestran los estudiantes antes y después del experimento? ¿Cuál es el nivel de reorganización de información e inferencia de significados (nivel inferencial) que muestran los estudiantes antes y después del experimento? ¿Cuál es el nivel de recuperación de reflexión sobre la forma, contenido y contexto (nivel crítico) que muestran los estudiantes antes y después del experimento?

\section{SUSTENTO TEÓRICO}

\subsection{Enfoque cognitivo, comunicativo y sociocultural}


"El enfoque cognitivo, comunicativo y sociocultural se sustenta en la concepción crítica del lenguaje, como capacidad humana que se adquiere en el proceso de socialización del individuo" (Roméu, 2006, pág. 21). Este enfoque es legatario de los postulados de la escuela histórico-cultural de Vygotsky (1995), que considera el lenguaje como un fenómeno social e histórico, "que revela la unidad de lo afectivo y lo cognitivo, lo interno y lo externo, el carácter activo de la conciencia y la relación de la enseñanza y el desarrollo" (Roméu, 2006, pág. 21). Es deudora de lo mejor de la lingüística del pasado siglo, que aportó a la investigación de la lengua como fenómeno social (Jakobson, Mathesius y otros). De igual forma, tiene en cuenta también las concepciones de Bakhtín acerca de su carácter ideológico y dialógico; "parte de la concepción de la cultura como un sistema de sistemas de signos, en el que la lengua desempeña un papel protagónico" (Lotman, 1979, pág. 22). Este enfoque analiza las manifestaciones culturales como procesos de comunicación, los que trascienden todos los espacios y contextos de comunicación social humana. Por otra parte, Eco (1977) revela la visión discursiva de la realidad (pensamiento, naturaleza y sociedad). A su vez, está indisolublemente vinculado a una concepción interdisciplinaria en los estudios del lenguaje, que tiene su origen en la propia naturaleza interdisciplinaria del conocimiento humano y que asume los postulados de la lingüística discursiva y el análisis del discurso, que ponen de relieve la relación entre el discurso, la cognición y la sociedad (Van Dijk, 1997).

Para Roméu (2006), en los momentos actuales, constituye una necesidad imperiosa la aplicación de un enfoque que acerque la enseñanza de la lengua al uso real que hacen de ella los hablantes.

El enfoque cognitivo-comunicativo y sociocultural da respuesta a esta aspiración, al revelar el nexo entre los procesos cognitivos y comunicativos, que expresan la unidad de la noesis y la semiosis, o sea, del pensamiento y el lenguaje, y su dependencia al contexto sociocultural donde tienen lugar dichos procesos. Si consideramos lo anterior, la enseñanza de la lengua implica por igual no sólo a aquellos profesores que enseñan lengua, sino a todos en general sin distinción de áreas, teniendo en cuenta que en su clase tienen lugar procesos cognitivos y comunicativos que ellos deben saber dirigir, y el papel que le corresponde a cada uno en el desarrollo sociocultural de sus alumnos como problema interdisciplinario (Roméu, 2006, pág. 22).

La lingüística del habla (del texto o del discurso), a diferencia de la lingüística de la lengua, da cuenta de los procesos cognitivos, la interacción y las estructuras sociales, de ahí que se establezca relaciones con múltiples disciplinas, con las que se vincula en el abordaje de su objeto de estudio, que no se limita al lenguaje en sí, sino que asume este en su accionar en los procesos cognitivos, metacognitivos y comunicativos en el ámbito social.

El discurso, la cognición y la sociedad, al decir de Van Dijk, conforman un triángulo, como resultado de la integración de tres enfoques principales: a) el que se concentra en las estructuras del texto y la conversación; b) el que estudia el discurso y la comunicación como cognición y c) el que se concentra en la estructura social y la cultura. "Esta figura triangular, cuyos vértices son el discurso, la cognición y la sociedad constituye, de hecho, el terreno del análisis multidisciplinario del discurso" (Van Dijk, 2000, pág. 52).

Estos enfoques están vinculados entre sí, por lo que conforman una tríada dialéctica, ya que no resulta posible explicar uno sin tener en cuenta los otros dos. Al respecto, Van Dijk señala que "no es posible explicar la estructura del texto y la interacción en ausencia de un enfoque cognitivo. Igualmente, no es posible dar cuenta de la cognición sin comprender que el conocimiento y otras 
creencias se utilizan en el discurso y en los contextos sociales. Asimismo, la cognición, la sociedad y la cultura, así como su reproducción, necesitan del lenguaje, del discurso y de la comunicación" (Van Dijk, 2001, pág. 23). A partir de esta concepción integrada, la descripción, el análisis y la explicación deben transitar por todos los vértices del triángulo y revelar las relaciones que existen entre ellos.

\section{El enfoque cognitivo, comunicativo y sociocultural es:}

El medio esencial de cognición y comunicación social, lo que pone de manifiesto su dos funciones esenciales: la noética o cognitiva y la semiótica o comunicativa; toma en cuenta los postulados de la escuela histórico-cultural acerca de la adquisición social del lenguaje, el proceso de internalización, la relación significado-sentido; tiene en cuenta lo mejor de la lingüística precedente, y las más recientes investigaciones de la lingüística del habla, que asumen como objeto el discurso e indagan acerca de su estructura y funciones, y explican su naturaleza como proceso de interacción social. De igual forma, defiende la concepción de la cultura como un sistema de sistemas de signos, en el que la lengua desempeña un papel protagónico. Este enfoque permite analizarlos procesos culturales como procesos de comunicación de significados, los que trascienden todos los espacios y contextos de comunicación social humana. A su vez, está indisolublemente vinculado a una concepción interdisciplinaria, que tiene su origen en la propia naturaleza interdisciplinaria del conocimiento humano (Roméu, 2006).

El enfoque cognitivo, comunicativo y socioculturales una construcción teórica, resultado del complejo proceso de desarrollo de las nuevas concepciones lingüísticas que centran su atención en el discurso y en los procesos de comprensión y producción de significados en diferentes contextos que, en nuestro ámbito, se interpretan a la luz de la psicología y la pedagogía crítica, que se ha ido construyendo a partir de sus aplicaciones (Carranza, 1995). Tiene un carácter interdisciplinario y se basa en teorías lingüísticas y didácticas que asumen respectivamente la investigación del discurso para su enseñanza. Se toman, a partir de una concepción interdisciplinaria, la ciencia del texto, el análisis del discurso, la semántica, la semiótica, la estilística, la etnometodología, la etnografía, la pragmática, la sociolingüística y la psicolingüística. A partir de los resultados de la lingüística del texto o lingüística textual, que explica las relaciones entre las dimensiones sintáctica, semántica y pragmática del texto, ha sido posible demostrar la pertinencia de las estructuras lingüísticas en dependencia de la intención comunicativa del emisor y lo que este quiere significar en un contexto dado. Dicho enfoque, se rige por las teorías didácticas más avanzadas, que asumen una didáctica desarrolladora desde el punto de vista integral, el paradigma sociocultural (Roméu, 2006).

Este enfoque dirigido a la educación en general surge en la primera mitad del siglo XX, como respuesta a las propuestas conductistas sobre el aprendizaje. Se basa en el análisis de los procesos del conocimiento del hombre. Sostiene que todo conocimiento es el resultado de la búsqueda y la acción del sujeto sobre su entorno, y no puede concebirse como mera transmisión desde fuera o cualidad inherente de la psique originada en el entorno. El aprendizaje se produce en una relación activa del sujeto sobre el objeto, porque todo conocimiento humano es una construcción personal del sujeto que parte de los datos sensoriales (Aguilar, 2011).

Según Aguilar (2011) este enfoque como método de análisis tiene sus antecedentes en los años 70 del siglo XX, propugnado por los lingüistas Bajtín, Todorov, Teun Van Dijk, Halliday, 
Bremond, Greimas, entre otros. Consiste en el análisis textual y no oracional. Es decir, considera como unidad mínima de comunicación al texto y no a la oración. Al respecto Cáceres Chaupín señala: "no nos comunicamos con oraciones aisladas, sino con textos; es decir, con estructuras en las que intervienen factores lingüísticos y contextuales, pues cuando realizamos la 'textificación' unimos una oración con otra mediante relaciones de coherencia, e inmersos en un determinado contexto situacional"' (Cáceres, 2007, pág. 5).

El enfoque cognitivo consiste en la ejecución de determinados procesos cognitivos al momento de interpretar un texto. Estos procesos cognitivos circundan las acciones de organización (macroestructura y superestructura), identificación de significados (tópico y comentario) y coherencia (global, local y pragmática). Sobre el texto y los procesos cognitivos Van Dijk señala: "Para la ciencia del texto es importante obtener una explicación de cómo los hablantes son capaces de leer o de oír manifestaciones linguísticas tan complejas como lo son los textos, de entenderlos, extraer ciertas informaciones, almacenar estas informaciones y volver a reproducirlas, según las tareas, las intenciones o los problemas concretos que se presenten" (Van Dijk, La ciencia del texto Editorial, 1978, pág. 20). Por otro lado, respecto al enfoque cognitivo, Angelina Roméu manifiesta: "el enfoque cognitivo es un medio de cognición y comunicación social que pone de manifiesto sus dos funciones esenciales: la noética o cognitiva y la semiótica o comunicativa" (Roméu, 2006). Desde el punto de vista psicológico, los procesos cognitivos: "son construcciones de la experiencia personal en forma de significados o supuestos personales que guían la conducta y las emociones" (Duviols, 2010).

El enfoque cognitivo es una construcción teórica, resultado del complejo proceso de desarrollo de las nuevas concepciones lingüísticas que centran su atención en el discurso y en los procesos de comprensión y producción de significados en diferentes contextos que, en nuestro ámbito, se interpretan a la luz de la psicología y la pedagogía, según los postulados de la Escuela histórico cultural, y los más recientes aportes de la didáctica desarrolladora, que se ha ido construyendo a partir de sus aplicaciones. Tiene un carácter interdisciplinario y se basa en teorías lingüísticas y didácticas que asumen respectivamente la investigación del discurso para su enseñanza. Se toman, a partir de una concepción interdisciplinaria, la ciencia del texto, el análisis del discurso, la semántica, la semiótica, la estilística, la etnometodología, la etnografía, la pragmática, la sociolingüística y la psicolingüística. A partir de los resultados de la lingüística del texto o lingüística textual, que explica las relaciones entre las dimensiones sintáctica, semántica y pragmática del texto, ha sido posible demostrar la pertinencia de las estructuras lingüísticas en dependencia de la intención comunicativa del emisor y lo que este quiere significar en un contexto dado (Aguilar, 2011).

Dicho enfoque, se rige por las teorías didácticas más avanzadas, que asumen una didáctica desarrolladora desde el punto de vista integral, el paradigma sociocultural (Aguilar, 2011).

El enfoque cognitivo se apoya en los resultados de las investigaciones de los psicólogos cognitivistas acerca de los procesos implicados en la comprensión y construcción de significados, que han arrojado múltiples datos, que han alcanzado gran difusión en el ámbito de la ciencia, así como su aplicación a la docencia. Tal es el caso de las llamadas estrategias de lectura, las macrorreglas de reducción de la significación, la teoría del modularidad para procesar la sintaxis y otros modelos cognitivos del discurso, así como de las estrategias metacognitivas que le permiten autorregular el proceso de significación (plantearse un objetivo, seleccionar estrategias, autorregular el proceso). De igual forma, asume las concepciones acerca de la lengua como 
ideología que reconoce el carácter dialógico y polifónico de la comunicación y que contempla la relación con el otro, así como los componentes afectivos, motivacionales, creativos y axiológicos que se revelan a través de ella (Aguilar, 2011).

A partir de los resultados de la lingüística del texto o lingüística textual, que explica las relaciones entre las dimensiones sintáctica, semántica y pragmática del texto, ha sido posible demostrar la pertinencia de las estructuras lingüísticas en dependencia de la intención comunicativa del emisor y lo que este quiere significar en un contexto dado.

Finalmente, el enfoque cognitivo, comunicativo y sociocultural, de acuerdo con los planteamientos de Angelina Roméu (2006), se sustenta en: a) La teoría de la codificación dual, sostiene que los seres humanos codifican la información tanto en formatos verbales como no verbales. Si se atienden ambos formatos, la información es más fácil de retener y de recordar. b) La teoría de los esquemas, afirma que dentro de la memoria humana existen esquemas o redes de información. El uso de Esquemas cognitivos puede ayudar a los estudiantes a enlazar el conocimiento existente, organizado en esquemas, con el conocimiento nuevo. c) La teoría de la carga cognitiva, sugiere que la carga o capacidad de la memoria de trabajo, tiene un tope máximo en la cantidad de información que puede procesar. Si esa carga se excede, el aprendizaje no se produce. Si los esquemas cognitivos se usan apropiadamente, puede reducirse la carga cognitiva y, en consecuencia, permitir que más recursos de la memoria de trabajo se dediquen al aprendizaje.

\section{Ventajas de su utilización}

La utilización del enfoque cognitivo y sociocultural permite según Angelina Roméu (2006): clarificar el pensamiento, reforzar la comprensión, integrar nuevo conocimiento, retener y recordar nueva información, identificar conceptos erróneos, evaluar, desarrollar habilidades de pensamiento de orden superior...

\section{Dimensiones del enfoque cognitivo, comunicativo y sociocultural}

\section{a) Discurso como cognición (Dimensión cognitiva):}

Mediante esta dimensión "se revela una de las funciones esenciales del lenguaje, la función noética, que se hace patente en la participación del lenguaje en la construcción del pensamiento en conceptos, lo que constituye la unidad dialéctica del pensamiento verbal y el lenguaje intelectual" (Roméu, 2006, pág. 36). El concepto de cognición se emplea en diferentes sentidos. Puede entenderse como los conocimientos que la persona posee y oponerse a los sentimientos, o aludir a los procesos mentales mediante los cuales se construyen los significados y se genera el sentido y el lenguaje, en lo que está implicado tanto lo cognitivo como lo afectivo. Tempranamente, Vigotsky advirtió acerca de la relación entre lo cognitivo y lo afectivo de la personalidad, concepción que en la actualidad es asumida, cada vez más, por los teóricos del cognitivismo, quienes "intentan integrar las emociones al funcionamiento de la cognición" (Charaudeau, 2001, pág. 18), a fin de revelar en su unidad dialéctica los componentes cognitivo y afectivo-emocional de la personalidad.

Los indicadores de la dimensión cognitiva son los conocimientos, habilidades, capacidades

y convicciones relacionados con el procesamiento de información, mediante los cuales las 
personas comprenden y producen significados. Se incluyen como indicadores: la comprensión y producción de significados, la aplicación de estrategias para obtener, evaluar y aplicar la información y otros.

Por otro lado, la cognición de textos se sustenta en el estudio de la macroestructura y superestructura, llamadas también estructuras abstractas. Tenemos la macroestructura, microestructura y la superestructura.

\section{b) Estructuras del texto y conversación (Dimensión comunicativa)}

La dimensión comunicativa pone de manifiesto la segunda función esencial del lenguaje: la semiótica. En esta perspectiva, el lenguaje se define como un sistema de signos que participan en la comunicación social, lo que implica saberes lingüísticos, sociolingüísticos, discursivos y estratégicos. Consiste en reconocer y usar el código lingüístico y otros códigos (gestual, icónico, simbólico, proxémico, etc.), y las reglas que rigen las relaciones entre los signos; saber utilizarlos en diferentes situaciones y contextos de comunicación; construir discursos coherentes y emplear estrategias que permitan iniciar, desarrollar y concluir la comunicación de forma exitosa (Roméu, 2006). Los indicadores de la dimensión comunicativa son los conocimientos, habilidades, capacidades y convicciones relacionados con los códigos, los signos y las reglas sintácticas que permiten relacionarlos, su adecuación a las exigencias del contexto, el discurso y su estructura, la tipología de los discursos y las estrategias para iniciar, desarrollar y concluir la comunicación. Comprende el saber y saber-hacer en términos de construcción gramatical.

\section{c) Estructura social y cultural (Dimensión social)}

La dimensión sociocultural está referida al conocimiento del contexto, los roles de los participantes, su jerarquía social, su ideología; están implicados, igualmente, la identidad de los sujetos, sus sentimientos y estados de ánimo, su pertenencia a una clase o grupo social, su intención y finalidad comunicativa y la situación comunicativa en la que tiene lugar la comunicación (Roméu, 2006). Los estudios más profundos acerca del contexto han sido los realizados por Teun van Dijk, quien ha desarrollado una Teoría del contexto, mediante la cual explica cómo los participantes son capaces de adaptar la producción y la recepción/interpretación del discurso a la situación comunicativo-interpersonal social (Van Dijk, 1980). Considera que la situación socialcomunicativa es en sí una noción sociocultural, que no influye directamente en las estructuras verbales/discursivas, pues se necesita de una interfaz sociocognitiva, que permite revelar la representación mental en cada participante de dichas estructuras.

\subsection{Comprensión de textos}

Es un proceso interactivo entre el lector y el texto. "La lectura es un instrumento indispensable para el desarrollo del ser humano por ser un medio de información, conocimientos e integración" (Sanchez, 2007). La comprensión de textos debe entenderse como un proceso gradual y estratégico de creación de sentido a partir de la interacción del lector con el texto en un contexto particular, interacción que está mediada por su propósito de lectura, sus expectativas y su conocimiento previo, donde este proceso pueda ser literal, inferencial o crítico reflexivo y/o 
también de un nivel independiente, instruccional y dependiente; según los factores que intervienen en el proceso de comprensión lectora como las habilidades, cualidades, saberes previos, atención, memoria, bagaje lexical del lector (Peralta, 2005).

Para Zanabria (2009), es el proceso de aprehensión de determinadas clases de información contenidas en un soporte particular que son transmitidas por medio de ciertos códigos, como lo puede ser el lenguaje. Es decir, un proceso mediante el cual se traducen determinados símbolos para su entendimiento. Se puede optar por códigos de tipo visual, auditivo e incluso táctil, como ocurre con el Braille, un método que utilizan los no videntes. Cabe destacar que existen alternativas de lectura que no necesariamente se respaldan en el lenguaje, como sucede por ejemplo con los pictogramas o la notación. La mecánica de la lectura implica la puesta en marcha de varios procesos. La fisiología, por ejemplo, ofrece la posibilidad de analizar y entender la capacidad de lectura del ser humano desde una perspectiva biológica (estudiando el ojo y la habilidad para fijar la visión) (Marrufo, 2009). La psicología, por su parte, contribuye a conocer el proceso que se pone en funcionamiento en la mente cuando alguien lee, tanto para interpretar símbolos, caracteres e imágenes como en la asociación de la palabra con lo que ese término representa (Sanchez, 2007).

La lectura consta, básicamente, de cuatro pasos: la visualización (un proceso discontinuo, ya que la mirada no se desliza de manera continua sobre las palabras), la fonación (la articulación oral, consciente o inconsciente, a través de la cual la información pasa de la vista al habla), la audición (la información pasa al oído) y la cerebración (la información llega al cerebro y culmina el proceso de comprensión). Existen diversas técnicas a la hora de iniciar una lectura, que permiten adaptar la forma de leer al objetivo que desea alcanzar el lector. Generalmente, se busca maximizar la velocidad o la comprensión del texto. Como estos objetivos son contrarios y se enfrentan entre sí, la lectura ideal implica un equilibrio entre los dos.

La lectura ofrece muchas ventajas para quienes la toman como un hábito imprescindible en sus vidas. Entre algunas de las riquezas que produce se encuentra, un enriquecimiento del universo interno y de la comprensión de otras realidades, adquisición de conocimientos que podrían servirnos, mejoramiento de nuestra capacidad comunicativa (sobre todo si se realiza una lectura oral) y colaborar con el desarrollo de la capacidad de análisis, resolución de problemas y asociaciones. Además, no debemos olvidar que es una fuente de entretenimiento apto para todas las edades, sexos y condición social. El secreto para apasionarse con la lectura reside en saber encontrar aquello que se adapta a nuestros deseos, intereses y necesidades (Vildoso, 2010).

Para que la lectura sea provechosa es muy importante que previamente se conozca el propósito de dicha actividad, cuál es la razón por la que deseamos leer; una vez hemos resuelto esto podemos buscar materiales que nos permitan alcanzar dicho objetivo y predisponernos para una lectura satisfactoria.

\section{Dimensiones de la comprensión de textos}

\section{a) La recuperación de información (nivel literal)}

Entender lo que el texto dice. (Información explícita). Por comprensión literal se entiende el reconocimiento y el discernimiento del significado de toda aquella información que se presenta explícitamente en el texto. Este tipo de comprensión es la que comúnmente se emplea en las escuelas de nivel primario, pues la enseñanza está más volcada a que los niños busquen lo que se 
considera las ideas o información más importante de un texto y a que logren una buena comprensión textual (Catala, 2016).

\section{b) La reorganización de información e inferencia de significados (nivel inferencial)}

Elaboración de ideas o elementos que no están expresados explícitamente en el texto. (Información implícita). Este componente "se ejerce cuando se activa el conocimiento previo del lector y se formulan anticipaciones o suposiciones sobre el contenido del texto a partir de los indicios que proporciona la lectura" (Catala, 2016, pág. 17). Es decir, permite ir más allá del propio texto y establecer una interacción entre el lector y el autor.

\section{c) La reflexión sobre la forma, contenido y contexto (nivel crítico)}

Capacidad para darse cuenta de que no se está entendiendo lo que se lee y aplicación de estrategias que regulen la comprensión. Esta dimensión "implica una formación de juicios propios, con respuesta de carácter subjetivo, una identificación con los personajes del libro, con el lenguaje del autor, una interpretación personal a partir de las reacciones creadas basándose en las imágenes literarias" (Catala, 2016, pág. 21).

\section{MÉTODO Y MATERIALES}

La investigación se realizó en la Institución Educativa Secundaria Independencia; ubicada en la ciudad, provincia y departamento de Puno. El periodo fue durante el segundo trimestre del año lectivo 2018. La población estaba constituida por todos los estudiantes que cursan el segundo grado de secundaria de la Institución Educativa Secundaria Independencia, Puno. De ellos se sacó como muestra a los estudiantes de los grupos A y B (64 estudiantes).

El tipo de investigación fue experimental (Palomino, 2004), tuvo como finalidad comprobar la eficacia del enfoque cognitivo, comunicativo y sociocultural. La investigación experimental se caracteriza por el desarrollo de un tratamiento o experimento (Hernández, Fernández, \& Baptista, 2010). El diseño que se utilizó en la investigación fue cuasi - experimental, con dos grupos, el grupo de control y el grupo experimental (Hernández, Fernández, \& Baptista, 2010). Una investigación es cuasi experimental cuando se concreta una comparación entre dos o más grupos, cuya selección no fue aleatoria, entendiendo que en uno de los grupos se realiza un tratamiento experimental (Palomino, 2004).

El plan del procedimiento del experimento fue como sigue:

- $\quad$ PRIMERO. Se tomó, de forma paralela, una prueba evaluativa de entrada al grupo de control y al grupo experimental para conocer el nivel de comprensión de textos.

- SEGUNDO. Se desarrolló el experimento con el grupo experimental, considerando la planificación de sesiones de aprendizaje.

- TERCERO. Se presentó en cada sesión a desarrollar, diferentes procesos y niveles de comprensión de textos.

- CUARTO. Se tomó una prueba de salida al grupo de control y experimental, para comprobar los resultados. 
- QUINTO. Se ubicaron los datos en cuadros analíticos generales para ser analizados e interpretados sistemáticamente.

- SEXTO. Se indagó la diferencia de la prueba de entrada y salida del grupo de control con el grupo experimental (tratamiento), aplicando el diseño estadístico planteado: $Z$ calculada.

- SÉPTIMO. Se comprobó la eficacia del enfoque cognitivo, comunicativo y sociocultural.

En cuanto al tratamiento de datos, se siguieron los siguientes pasos:

- Se midió los resultados de la prueba de entrada de ambos grupos de control y experimental.

- Se sistematizó el proceso de resultados de las sesiones del grupo experimental

- Se midieron los resultados de la prueba de salida de ambos grupos de control y experimental y se realizó una contrastación con el diseño estadístico.

Variables de investigación

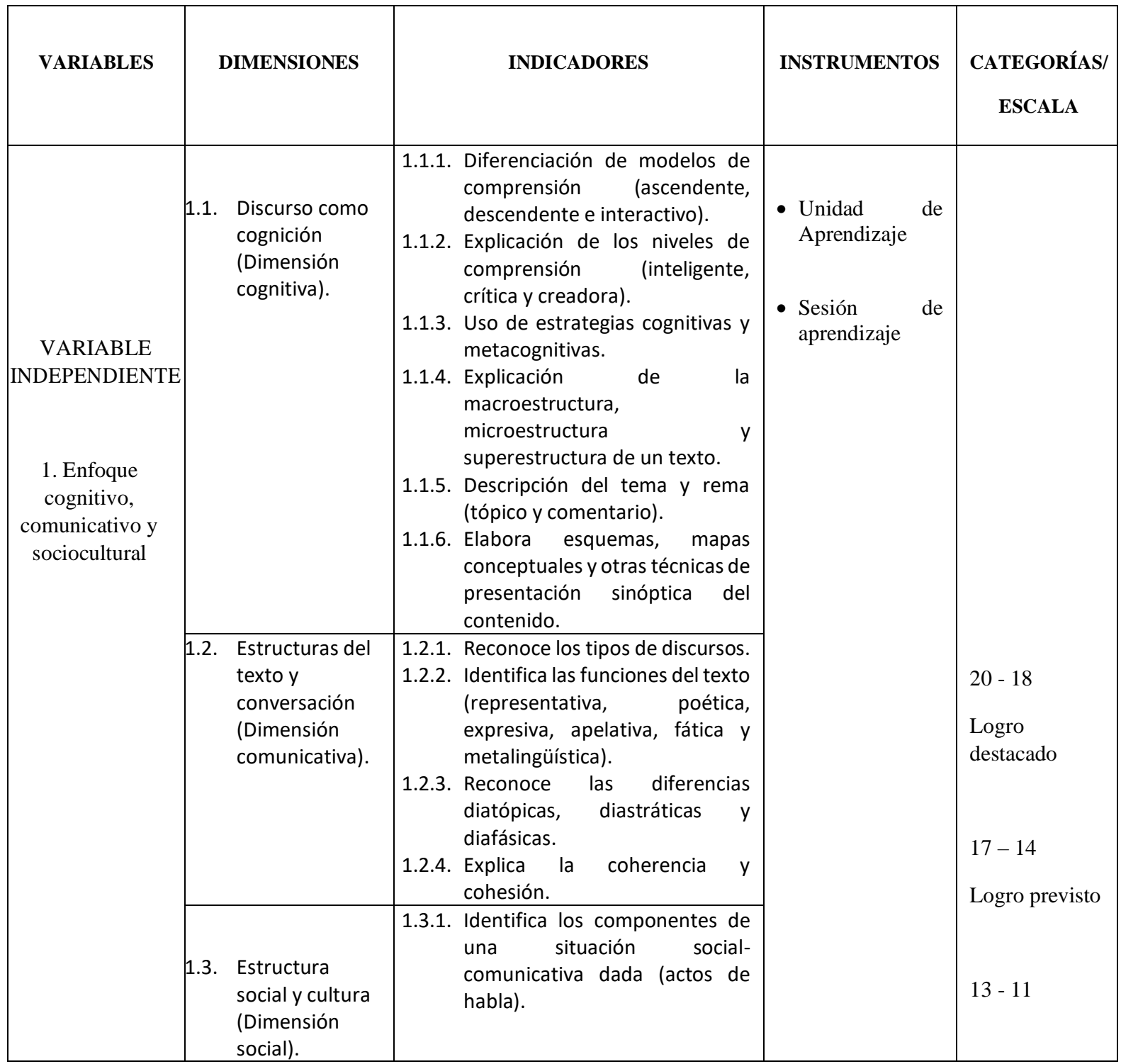




\begin{tabular}{|c|c|c|c|c|}
\hline & & \begin{tabular}{|l} 
1.3.2. \\
Reconoce el carácter complejo \\
del contexto y sus \\
componentes. \\
1.3.3. $\begin{array}{l}\text { Diferencia los roles de los } \\
\text { participantes }\end{array}$ \\
\end{tabular} & & $\begin{array}{l}\text { En proceso } \\
10-00\end{array}$ \\
\hline \multirow{3}{*}{$\begin{array}{l}\text { VARIABLE } \\
\text { DEPENDIENTE } \\
\text { 2. Comprensión } \\
\text { de textos }\end{array}$} & $\begin{array}{ll}\text { 2.1. } & \text { Recuperación } \\
\text { de información } \\
\text { (nivel literal). }\end{array}$ & $\begin{array}{l}\text { 2.1.1. } \begin{array}{l}\text { Identificación la idea principal } \\
\text { explícita. }\end{array} \\
\text { 2.1.2. } \\
\begin{array}{l}\text { Identificación de personajes } \\
\text { principales y secundarios. }\end{array} \\
\text { 2.1.3. } \\
\text { Reconocimiento de relaciones } \\
\text { de causa consecuencia. }\end{array}$ & \multirow[t]{3}{*}{$\begin{array}{l}\text { Prueba escrita de } \\
\text { entrada y salida }\end{array}$} & \multirow[t]{3}{*}{ En inicio } \\
\hline & 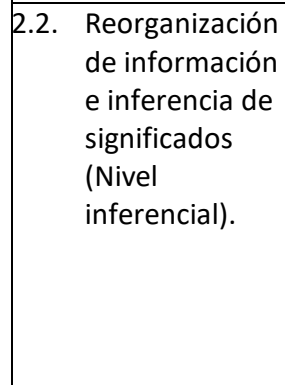 & 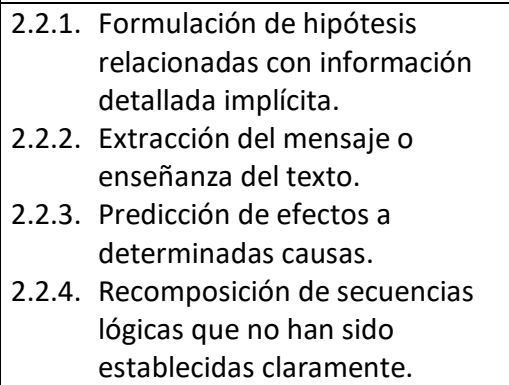 & & \\
\hline & $\begin{array}{l}\text { 2.3. } \\
\text { Reflexión sobre } \\
\text { la forma, } \\
\text { contenido y } \\
\text { contexto (Nivel } \\
\text { crítico). }\end{array}$ & 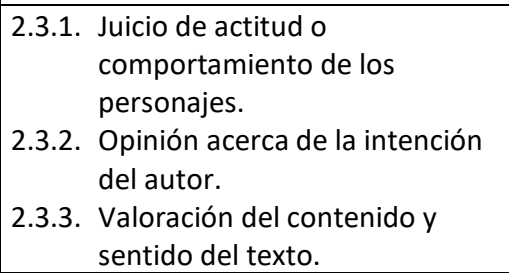 & & \\
\hline
\end{tabular}

\section{RESULTADOS}

\subsubsection{La comprensión de textos antes del tratamiento experimental en los grupos experimental y control}

Antes de la intervención experimental se aplicó a los dos grupos de investigación (experimental y control) una prueba de entrada para comprobar el nivel de comprensión de textos, considerando la escala cualitativa y cuantitativa, determinada por el Ministerio de Educación.

Tabla 1. Nivel de comprensión de textos de los estudiantes del segundo grado antes del tratamiento experimental en los grupos experimental y control

\begin{tabular}{|c|c|c|c|c|c|}
\hline \multicolumn{2}{|c|}{ ESCALAS } & \multicolumn{2}{|c|}{$\begin{array}{c}\text { GRUPO } \\
\text { EXPERIMENTAL }\end{array}$} & \multicolumn{2}{|c|}{ GRUPO CONTROI } \\
\hline $\begin{array}{c}\text { ESCALA } \\
\text { CUALITATIVA }\end{array}$ & $\begin{array}{c}\text { ESCALA } \\
\text { CUANTITATIVA }\end{array}$ & fi & $\%$ & fi & $\%$ \\
\hline Logro destacado & $18-20$ & 0 & $0 \%$ & 0 & $0 \%$ \\
\hline Logro previsto & $14-17$ & 3 & $9 \%$ & 2 & $6 \%$ \\
\hline En proceso & $11-.13$ & 12 & $38 \%$ & 11 & $34 \%$ \\
\hline En inicio & $0-10$ & 17 & $53 \%$ & 19 & $59 \%$ \\
\hline \multicolumn{2}{|c|}{ TOTAL } & 32 & $100 \%$ & 32 & $100 \%$ \\
\hline
\end{tabular}

FUENTE: Prueba de entrada 


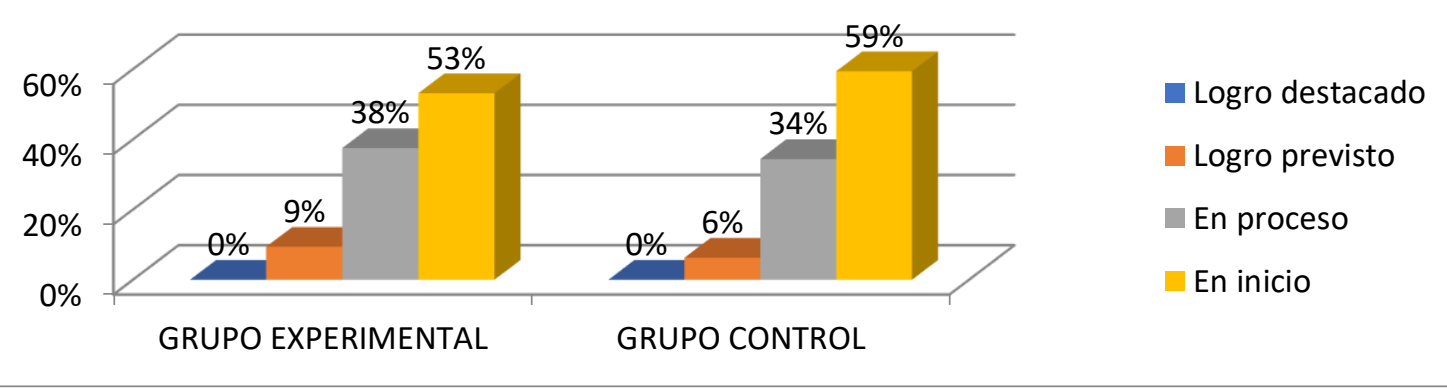

Figura 1. Nivel de comprensión de textos de los estudiantes del segundo y tercer grado antes del tratamiento experimental en los grupos experimental y control

En la tabla 1 y figura 1, se presenta los resultados de la prueba de entrada de los estudiantes del grupo experimental y de control en COMPRENSIÓN DE TEXTOS. Se puede observar que en la escala LOGRO DESTACADO, tanto en el grupo experimental como de control no se ubica ningún estudiante (0\%). En la escala de LOGRO PREVISTO, en el grupo experimental se ubican 3 estudiantes (9\%) y en el grupo control se ubican 2 estudiantes (6\%). En la escala EN PROCESO, en el grupo experimental existen 12 estudiantes (38\%), mientras que en el grupo de control se ubican 11 estudiantes (34\%). En la escala EN INICIO, en el grupo experimental se ubican 17 estudiantes (53\%), mientras que en el grupo de control se ubican 19 estudiantes (59\%). Estos resultados indican que, en la prueba de entrada, ambos grupos se encontraron con los mismos problemas, por ello las frecuencias son similares.

Mediante un análisis comparativo, Marrufo (2009) también encontró en su experimento que antes del desarrollo de talleres de lengua (LUZ), se ha detectado la dificultad que tienen los estudiantes para comprender un texto en un $76 \%$. Esto los hace apáticos a la revisión bibliográfica de exigencia académica o de cualquier material útil para la formación y el desarrollo intelectual necesarios para acceder a capas más profundas y avanzadas de la cultura y la ciencia.

\subsubsection{La comprensión de textos después del tratamiento experimental en los grupos experimental y control}

Después de la intervención experimental se aplicó a los dos grupos de investigación (experimental y control) una prueba de salida para comprobar el nivel de comprensión de textos.

Tabla 2. Nivel de comprensión de textos de los estudiantes del segundo grado después del tratamiento experimental en los grupos experimental y control

\begin{tabular}{|c|c|c|c|c|c|}
\hline \multicolumn{2}{|c|}{ ESCALAS } & \multicolumn{2}{|c|}{$\begin{array}{c}\text { GRUPO } \\
\text { EXPERIMENTAL }\end{array}$} & \multicolumn{2}{|c|}{ GRUPO CONTROL } \\
\hline $\begin{array}{c}\text { ESCALA } \\
\text { CUALITATIVA }\end{array}$ & $\begin{array}{c}\text { ESCALA } \\
\text { CUANTITATIVA }\end{array}$ & $\mathbf{f i}$ & $\%$ & fi & $\%$ \\
\hline Logro destacado & $18-20$ & 7 & $22 \%$ & 0 & $0 \%$ \\
\hline Logro previsto & $14-17$ & 16 & $50 \%$ & 6 & $19 \%$ \\
\hline En proceso & $11-.13$ & 9 & $28 \%$ & 19 & $59 \%$ \\
\hline En inicio & $0-10$ & 0 & $0 \%$ & 7 & $22 \%$ \\
\hline \multicolumn{2}{|c|}{ TOTAL } & 32 & $100 \%$ & 32 & $100 \%$ \\
\hline
\end{tabular}

FUENTE: Prueba de salida 


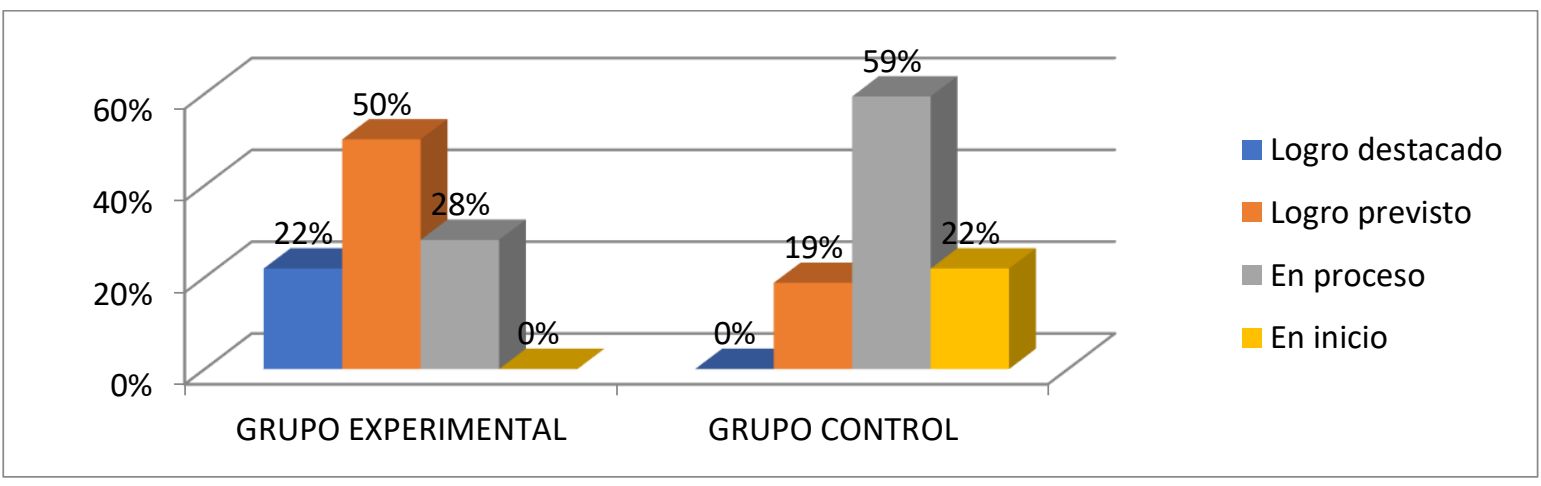

Figura 2. Nivel de comprensión de textos de los estudiantes del segundo grado después del tratamiento experimental en los grupos experimental y control

En la tabla 2 y figura 2, se presenta los resultados de la prueba de salida de los estudiantes del grupo experimental y de control en COMPRENSIÓN DE TEXTOS. Se puede observar que en la escala LOGRO DESTACADO en el grupo experimental se ubican 7 estudiantes (22\%) y en el grupo de control no se ubica ningún estudiante $(0 \%)$. En la escala de LOGRO PREVISTO, en el grupo experimental se ubican 16 estudiantes (50\%), mientras que en el grupo control se ubican 6 estudiantes (19\%). En la escala EN PROCESO, en el grupo experimental se ubican 9 estudiantes (28\%), mientras que en el grupo de control se ubican 19 estudiantes (59\%). En la escala EN INICIO, en el grupo experimental no se ubica ningún estudiante $(0,0 \%)$, mientras que en el grupo de control se ubican 7 estudiantes $(22 \%)$. Estos resultados indican que después del tratamiento experimental, los estudiantes del grupo experimental mejoraron en su ubicación de escala; lo que indica que la aplicación del enfoque cognitivo, comunicativo y sociocultural es efectivo para mejorar la comprensión de textos. Al analizar otro estudio, Peralta (2005), encontró también que los estudiantes después de la aplicación de su técnica, logró mejorar la comprensión de textos de manera excelente en un $65 \%$ del total de estudiantes.

\subsubsection{Resultados de las dimensiones}

Tabla 2. Resultados del nivel literal

\begin{tabular}{lccccc}
\hline \multicolumn{1}{c}{ ESCALAS } & \multicolumn{2}{c}{$\begin{array}{c}\text { PRUEBA DE } \\
\text { ENTRADA }\end{array}$} & PRUEBA DE SALIDA \\
\hline \multicolumn{1}{c}{ ESCALA } & ESCALA & fi & $\%$ & fi & $\%$ \\
CUALITATIVA & CUANTITATIVA & & & & $\%$ \\
\hline Logro destacado & $18-20$ & 0 & $0 \%$ & 9 & $28 \%$ \\
Logro previsto & $14-17$ & 5 & $16 \%$ & 14 & $44 \%$ \\
En proceso & $11-.13$ & 13 & $41 \%$ & 9 & $28 \%$ \\
En inicio & $0-10$ & 14 & $44 \%$ & 0 & $0 \%$ \\
\hline \multicolumn{2}{c}{ TOTAL } & 32 & $100 \%$ & 32 & $100 \%$ \\
\hline
\end{tabular}

FUENTE: Prueba de entrada y salida 


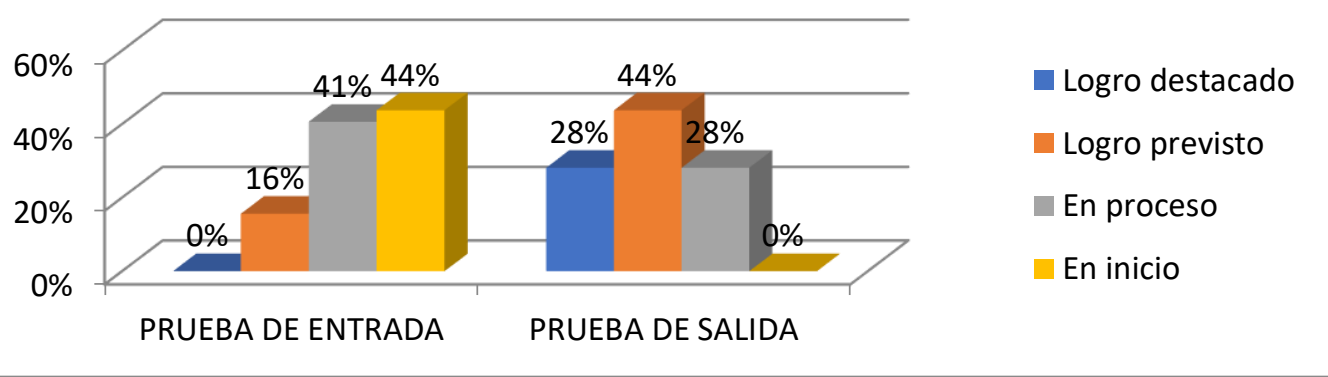

Figura 3. Resultados del nivel literal

Fuente: Tabla 13

En la tabla 3 y figura 3, se presenta los resultados de los estudiantes del grupo experimental en EL NIVEL LITERAL. Se puede observar que en la escala LOGRO DESTACADO, en la prueba de entrada no se ubica ningún estudiante $(0 \%)$, mientras que en la prueba de salida se ubican 9 estudiantes (28\%). En la escala de LOGRO PREVISTO, en la prueba de entrada se ubican 5 estudiantes (16\%), mientras que en la prueba de salida se ubican 14 estudiantes (44\%). En la escala EN PROCESO, en la prueba de entrada se ubica 13 estudiantes (41\%), mientras que en la prueba de salida se ubican 9 estudiantes (28\%). En la escala EN INICIO, en la prueba de entrada se ubican 14 estudiantes (44\%), mientras que en la prueba de salida se no se ubica ningún estudiante (0\%).

Tabla 3. Resultados del nivel inferencial

\begin{tabular}{lccccc}
\hline \multicolumn{1}{c}{ ESCALAS } & \multicolumn{2}{c}{$\begin{array}{c}\text { PRUEBA DE } \\
\text { ENTRADA }\end{array}$} & \multicolumn{2}{c}{$\begin{array}{c}\text { PRUEBA DE } \\
\text { SALIDA }\end{array}$} \\
\hline $\begin{array}{c}\text { ESCALA } \\
\text { CUALITATIVA }\end{array}$ & $\begin{array}{c}\text { ESCALA } \\
\text { CUATITATIVA }\end{array}$ & fi & $\%$ & $\mathbf{f i}$ & $\%$ \\
\hline Logro destacado & $18-20$ & 0 & $0 \%$ & 6 & $19 \%$ \\
Logro previsto & $14-17$ & 2 & $6 \%$ & 13 & $41 \%$ \\
En proceso & $11-.13$ & 9 & $28 \%$ & 10 & $31 \%$ \\
En inicio & $0-10$ & 21 & $66 \%$ & 3 & $9 \%$ \\
\hline \multicolumn{2}{c}{ TOTAL } & 32 & $100 \%$ & 32 & $100 \%$ \\
\hline
\end{tabular}

FUENTE: Prueba de entrada y salida

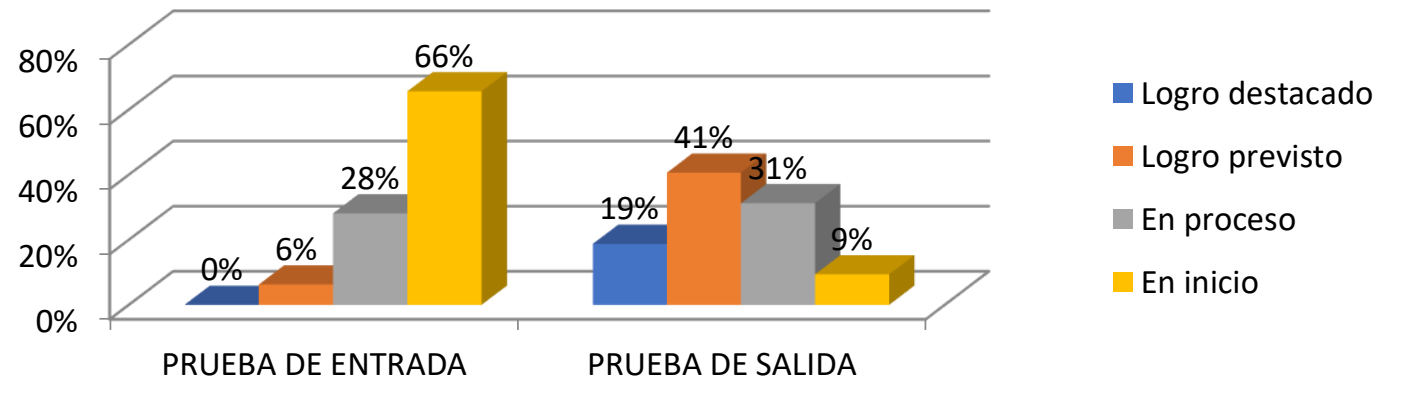

Figura 4. Resultados del nivel inferencial

Fuente: Tabla 14 
En la tabla 4 y figura 4, se presenta los resultados de los estudiantes del grupo experimental en EL NIVEL INFERENCIAL. Se puede observar que en la escala LOGRO DESTACADO, en la prueba de entrada no se ubica ningún estudiante $(0 \%)$, mientras que en la prueba de salida se ubican 6 estudiantes (19\%). En la escala de LOGRO PREVISTO, en la prueba de entrada se ubican 2 estudiantes (6\%), mientras que en la prueba de salida se ubican 13 estudiantes (41\%). En la escala EN PROCESO, en la prueba de entrada se ubica 9 estudiantes (28\%), mientras que en la prueba de salida se ubican 10 estudiantes $(31 \%)$. En la escala EN INICIO, en la prueba de entrada se ubican 21 estudiantes (66\%), mientras que en la prueba de salida se ubican 3 estudiantes (9\%).

Tabla 4. Resultados del nivel crítico

\begin{tabular}{|c|c|c|c|c|c|}
\hline \multicolumn{2}{|c|}{ ESCALAS } & \multicolumn{2}{|c|}{$\begin{array}{l}\text { PRUEBA DE } \\
\text { ENTRADA }\end{array}$} & \multicolumn{2}{|c|}{$\begin{array}{c}\text { PRUEBA DE } \\
\text { SALIDA }\end{array}$} \\
\hline $\begin{array}{c}\text { ESCALA } \\
\text { CUALITATIVA }\end{array}$ & $\begin{array}{c}\text { ESCALA } \\
\text { CUANTITATIVA }\end{array}$ & fi & $\%$ & fi & $\%$ \\
\hline Logro destacado & $18-20$ & 0 & $0 \%$ & 6 & $19 \%$ \\
\hline Logro previsto & $14-17$ & 2 & $6 \%$ & 13 & $41 \%$ \\
\hline En proceso & $11-.13$ & 10 & $31 \%$ & 10 & $31 \%$ \\
\hline En inicio & $0-10$ & 20 & $63 \%$ & 3 & $9 \%$ \\
\hline \multicolumn{2}{|c|}{ TOTAL } & 32 & $100 \%$ & 32 & $100 \%$ \\
\hline
\end{tabular}

FUENTE: Prueba de entrada y salida

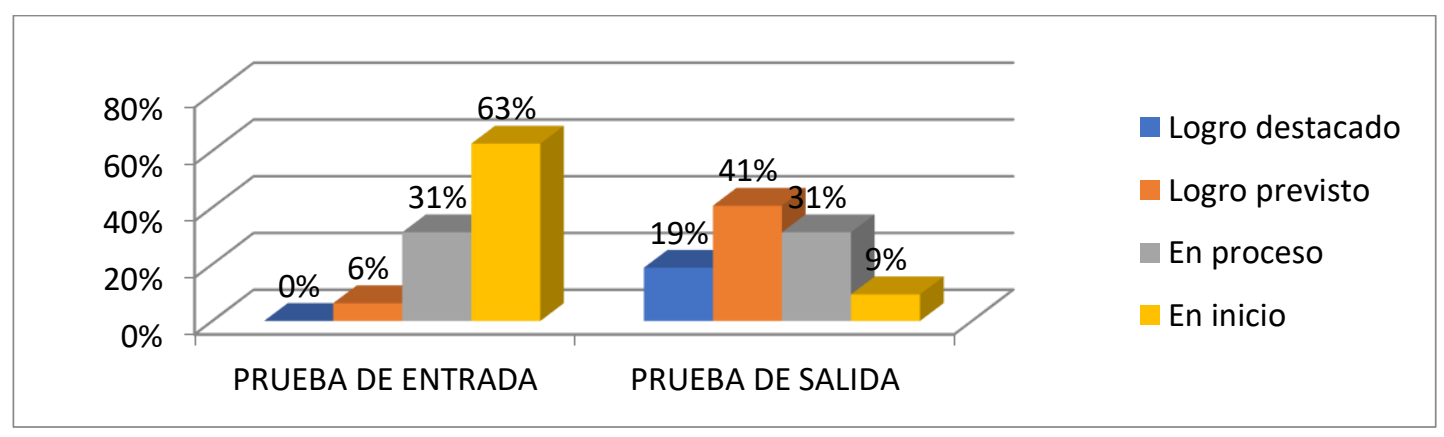

Figura 1. Resultados del nivel crítico

En la tabla 5 y figura 5, se presenta los resultados de los estudiantes del grupo experimental en EL NIVEL CRÍTICO. Se puede observar que en la escala LOGRO DESTACADO, en la prueba de entrada no se ubica ningún estudiante $(0 \%)$, mientras que en la prueba de salida se ubican 6 estudiantes (19\%). En la escala de LOGRO PREVISTO, en la prueba de entrada se ubican 2 estudiantes (6\%), mientras que en la prueba de salida se ubican 13 estudiantes (41\%). En la escala EN PROCESO, en la prueba de entrada se ubica 10 estudiantes (31\%), mientras que en la prueba de salida se ubican 10 estudiantes (31\%). En la escala EN INICIO, en la prueba de entrada se ubican 20 estudiantes (63\%), mientras que en la prueba de salida se ubican 3 estudiantes (9\%).

\section{DISCUSIÓN}

La investigación tuvo como propósito: determinar la eficacia del enfoque cognitivo, comunicativo y sociocultural en la comprensión de textos literarios en estudiantes de secundaria. 
La muestra fue seleccionada considerando criterios de opinión (intencional), debido a que la institución de estudio está ya estratificada por grados y secciones de estudio.

En el estudio realizado se encontró que el enfoque cognitivo, comunicativo y sociocultural mejora significativamente la comprensión de textos literarios en estudiantes del segundo grado de secundaria; esta aseveración quedó confirmada con los resultados de la prueba de salida, ya que, en ésta, los estudiantes predominantemente se ubican en la escala "Logro Previsto" con 16 estudiantes (50\%), mientras que en la prueba de entrada predominaba la escala "En Inicio" con 17 estudiantes (53\%). El promedio de la prueba de entrada fue de 7,19 y el de la prueba de salida fue 17.03. Asimismo, la confirmación de hipótesis arrojó una $\mathrm{Z}$ calculada superior a la $\mathrm{Z}$ tabla: $|15,58|>|1,96|$, por lo que se confirma la hipótesis estadística.

Otros estudios similares se acercan a los mismos resultados. Por ejemplo, Marrufo (2009) en su estudio encontró que los estudiantes tienen problemas para comprender un texto en un $76 \%$. Esto los hace apáticos a la revisión bibliográfica de exigencia académica o de cualquier material útil para la formación y el desarrollo intelectual necesarios para acceder a capas más profundas y avanzadas de la cultura y la ciencia.

Del mismo modo Oré (2012), en su estudio que el 31.5\% de los estudiantes se encuentra en un nivel dependiente-dificultad, el $43.5 \%$ se ubica en el nivel dependiente-malo y el $23.6 \%$ se encuentra en el nivel dificultad-pésimo. Los hábitos de estudio de los estudiantes en general tienen tendencia a ser positivos o adecuados en un 47.2\%. Sin embargo, el 37.5\% de los estudiantes muestran tendencia a ser negativos. El rendimiento académico de los estudiantes que se encuentran en el nivel regular (notas entre 11 y 13) es de 41.0\%; mientras que un 38.2\% de los estudiantes obtiene un nivel de rendimiento bueno (notas entre 14 y 17). Asimismo, Peralta (2005), encontró que el nivel de comprensión de lectura se ubica en un nivel deficiente (59\%), regular (31\%) y bueno $(10 \%)$.

Por otra parte, las nuevas líneas de investigación son el desarrollo del tópico y comentario, la deducción de significados en una lectura, la gramática del texto en instituciones educativas de la Región Puno. La investigación muestra validez de constructo, ya que se consideraron aspectos básicos del Ministerio de educación en comprensión Lectora. Por lo que se puede señalar que este estudio puede ser exteriorizado o replicado en contextos similares.

\section{CONCLUSIONES}

El enfoque cognitivo, comunicativo y sociocultural es eficaz en la comprensión de textos literarios en estudiantes del segundo grado de secundaria de la Institución Educativa Secundaria Independencia Nacional, Puno, 2018. Se llega a esta conclusión porque la Z calculada es superior a la $\mathrm{Z}$ tabla: $|15,58|>|1,96|$, por lo que se confirma la hipótesis alterna. Asimismo, en la prueba de salida los estudiantes predominantemente se ubican en la escala "Logro Previsto" con 16 estudiantes (50\%), mientras que en la prueba de entrada predominaba la escala "En Inicio" con 17 estudiantes (53\%). El promedio de la prueba de entrada fue de 7,19 y el de la prueba de salida fue 17.03.

El nivel de recuperación de información (nivel literal) que muestran los estudiantes antes del experimento se ubica en la escala "En Inicio" (44\%) y después del experimento se ubica en la escala "Logro Previsto" (44\%). 
El nivel de reorganización de información e inferencia de significados (nivel inferencial) que muestran los estudiantes antes del experimento se ubica en la escala "En Inicio" (66\%) y después del experimento se ubica en la escala "Logro Previsto" (41\%).

El nivel de recuperación de reflexión sobre la forma, contenido y contexto (nivel crítico) que muestran los estudiantes antes del experimento se ubica en la escala "En Inicio" (63\%) y después del experimento se ubica en la escala "Logro Previsto" (41\%).

\section{REFERENCIAS BIBLIOGRÁFICAS}

Aguilar, J. (2011). Método de Análisis basado en el Enfoque Cognitivo para la comprensión de textos literarios narrativos en los alumnos del tercer grado del Glorioso Colegio Nacional 'San Carlos' de la ciudad de Puno en el año 2011. Puno: Universidad Nacional del Altiplano.

Borneo, H. (1978). Gobierno y empresas públicas en América Latina. Anuario Jurídico, 5 - 33.

Burgallo, C. (2015, marzo 29). El estado Captalista. El Salmón contracorriente.

Cáceres, J. (2007). La producción de textos, gramática del texto. Lima: Liñán.

Caño, A., \& Luna, F. (2015). PISA: Comprensión Lectora, marco y análisis de los items. Asturias: ISEI, IVEI.

Carranza, J. (1995). Pedagogía y didáctica crítica. Retrieved agosto 29, 2017, from http://www.scielo.org.bo/pdf/rieiii/v2n1/n01a05.pdf

Catala, G. (2016). Evaluación de la compresión lectora. Barcelona: GRAO.

Charaudeau, P. (2001). De la competencia social de comunicación a las competencias discursivas. Maracaibo: Revista latinoamericana de estudios del discurso.

Contreras, C. (2013). El Perú baja dos puestos en educación: del 63 al 65. Retrieved enero 07, 2016, from http://larepublica.pe/04-12-2013/el-peru-baja-dos-puestos-en-educacion-del63-al-65

Duviols, H. (2010). Esquemas cognitivos. Retrieved noviembre 4, 2016, from http://www.abcpsicologia.com/los-esquemas-cognitivos/

Eco, H. (1977). Tratado de semiótica general. Barcelona: Lumen.

Faleto, E. (2014). La Especificidad del Estado en Améri ca Latina. Estudios(31), 205-236.

González Vigil, F. (s.f.). Capitalismo transnacional y capitalismo nacional en el Perú: Un ensayo retrospectivo. Retrieved Junio 28, 2018, from file:///C:/Users/HP/Downloads/DialnetCapitalismoTransnacionalYCapitalismoNacionalEnElPe-5014688\%20(3).pdf

Hernández, R., Fernández, C., \& Baptista, P. (2010). Metodología de la investigación (Quinta edición ed.). (J. Mares, Ed.) Ciudad de México, México D.F., México: Mc GRAW HILL.

Herrera, C. (2003). OCDE: el rendimiento escolar en México, sin mejoría en dos años. Retrieved junio 29, 2017, from http://www.grade.edu.pe/gtee-preal/recortes/eval577.htm

Jessop, B. (1997). Teorías recientes sobre el estado capitalista. Cambridge Journal of Economics, $353-373$.

Lotman, Y. (1979). Semiótica de la cultura. Madrid: Cátedra.

Mamani, E. (2003). Nivel de comprensión de la lectura y el rendimiento académico de los alumnos del tercer grado de educación secundaria del Colegio Nacional Agropecuario Manco Cápac del distrito de Paratía. Puno: Universidad Nacional del Altiplano.

Marrufo, J. (2009). Hábitos de lectura y competencias de comprensión de información escrita de alumnos del tercer año de Licenciatura de la Universidad. Yucatán: Universidad Patria.

Marx, C. (1995). El capital: crítica de la economía política. México: Fondo de Cultura económica.

Miguel, S., Bongiovani, P., Gómez, N., \& Bueno, G. (2013). Situación y perspectivas del desarrollo del Acceso Abierto en Argentina. Palabra Clave (La Plata), 2(2), 1-10. 
Miranda, T., Suset, A., Cruz, A., Machado, H., \& Campos, M. (2007). El Desarrollo sostenible. Perspectivas y enfoques en una nueva época. Pastos y Forrajes, 30(2), 191-204.

Mora Toscano, O. (2008). El Proceso de Transformación del Capitalismo Mundial. Momentos Conceptualizaciones y Consecuencias de Política Pública Ecómica y Social. Revistas UPTC, 27(45), 1-29.

Nicolau, M. (2016). Estrategia pedagógica para el desarrollo de la competencia comunicativa de los estudiantes de la Facultad de Turismo de la Universidad de La Habana, Cuba. Retrieved setiembre 20, 2017, from http://ecociencia.ecotec.edu.ec/articulo.php?ida=67

Núñez, J. (2010). Aproximación a la lingüística del texto. Puno: Letrajoven.

OCDE. (2010). PISA 2009, Programa para la evaluación internacional de alumnos. Retrieved junio 29, 2017, from http://www.mecd.gob.es/dctm/ievaluacion/internacional/pisa-2009con-escudo.pdf?documentId=0901e72b808ee4fd

OCDE. (2013). Resultados de PISA 2012 en foco. Retrieved Junio 28, 2017, from https://www.oecd.org/pisa/keyfindings/PISA2012_Overview_ESP-FINAL.pdf

OCDE. (2016). PISA 2015, Resultados clave. Retrieved junio 30, 2017, from https://www.oecd.org/pisa/pisa-2015-results-in-focus-ESP.pdf

O'Connor, J. (1981). La crisis fiscal del Estado. Barcelona: Península.

Oré, R. (2012). Comprensión lectora, hábitos de estudio y rendimiento académico en estudiantes de primer año de una universidad privada de Lima Metropolitana . Lima: Universidad Nacional Mayor de San Marcos.

Pacho, Y. (2006). Niveles de Comprensión Lectora. Lima: San Marcos.

Palomino, P. (2004). Diseños y técnicas de investigación educativa. Puno: Titikaka-Programa de Complementación Académica de la Facultad de Ciencias de la Educación de la UNA Puno.

Palomino, P. (2004). Diseños y técnicas de investigación educativa. Puno: Titikaka-Programa de Complementación Académica de la Facultad de Ciencias de la Educación de la UNA Puno.

Pannekoek, A. (s.f.). Capitalismo de Estado y dictadura. Retrieved Junio 29, 2018, from https://www.marxists.org/espanol/pannekoek/1937/dictadura.htm

Peralta, A. (2005). El nivel de comprensión de lectura en los alumnos de la I.E.S. José Teobaldo Paredes Valdez de Paucarpata en los alumnos del primer grado. Arequipa: Universidad Nacional San Agustín.

Pérez, H. (2006). Comprensión y producción de textos. Bogotá: Magisterio.

Pichs, R. (2002). Los retos del desarrollo sostenible en América Latina. Retrieved from http://www.redem.buap.mx/ramon.htm. .

Roméu, A. (2006). El enfoque cognitivo, comunicativo y sociocultural se sustenta en los principios. La Habana: Editorial pueblo y educación.

Sabogal, J. (2016). El modo de producción capitalista, su actual crisis sistémica y una alternativa posible. Sociedad y economía(28), 76-94.

Sanchez, D. (2007). Estrategias didácticas para la comprensión lectora: Didáctica de la lectura bases para la comprensión lectora. Lima: UNMSM Facultad de Educación Centro de Extensión Universitaria y Proyección Social.

Sarwat, J., \& Ahmed Saber , M. (2015). ¿Qué es el capitalismo? Retrieved Junio 28, 2018, from https://www.imf.org/external/pubs/ft/fandd/spa/2015/06/pdf/basics.pdf

Sierra, M. (2015, mayo 15). Capitalismo, desarrollo y Estado: una apreciación rápida. La Tribuna.

Smelser, N. (1984). Economy and Society: A study in the Integration of Economic and Social Theory. London: 1st Edition.

Smith, F. (2000). Estrategias de Lectura. En: "Enseñar Lengua” de Cassany Daniel . Bogotá: Audiebro.

Tamayo, J. S. (2016). El modo de producción capitalista, su actual crisis sistémica y una alternativa posible. Sociedad y economía(28), 76-94.

Tamayo, M. (2003). El proceso de la investigación científica. México D.F.: LIMUSA. 
Taylor, L. (2004). Reconstructing Macroeconomics. Structuralist Proposals and Critiques of the Mainstream. Cambridge: Harvard University Press.

Van Dijk, T. (1978). La ciencia del texto Editorial. México D.F.: Paidos.

Van Dijk, T. (1980). Texto y contexto. Madrid: Cátedra.

Van Dijk, T. (1997). Discurso, cognición y sociedad. Barcelona: Routledge.

Van Dijk, T. (2000). El estudio del discurso. Retrieved setiembre 19, 2017, from http://padron.entretemas.com.ve/cursos/AdelD/unidad1/1EstudioDiscurso.pdf

Van Dijk, T. (2001). El discurso como estructura y proceso. Estudios sobre el discurso. Barcelona: Gedisa.

Vildoso, S. (2010). Influencia de los Hábitos de Estudio y la Autoestima en el Rendimiento Académico de los Estudiantes de la Escuela profesional de agronomía de la Universidad Nacional Jorge Basadre Grohman. Lima: Universidad Nacional Mayor San Marcos.

Vygotsky, L. (1995). Pensamiento y lenguaje. México: Ediciones Fausto.

Wallerstein, I. (1988). El capitalismo histórico. México: Siglo XXI.

Zanabria, C. (2009). Hábitos de lectura en el primer ciclo de preparatoria. México: Liceo Tenochtitlán.

Anexo A.

PRUEBA DE ENTRADA

NOMBRES Y APELLIDOS:

GRADO Y SECCIÓN:.

.FECHA

I. LEE ATENTAMENTE EL SIGUIENTE TEXTO:

En este apartado se presentó la lectura:

LA VENGANZA DEL CÓNDOR (Ventura García Calderón)

\section{RESPONDE ADECUADAMENTE A LAS SIGUIENTES PREGUNTAS:}

1. NIVEL LITERAL (6 puntos)

1.1. ¿Cuál es la idea más importante del tercer párrafo "La Venganza del Cóndor"?

a) La identificación de los indios

b) El hecho de que el militar le rasgó la frente al indio de un latigazo

c) El sueño del indio en su aposento

d) Ninguna de las anteriores

1.2. ¿Cuáles son los personajes principales y secundarios?

a) Principal: El indio; Secundarios: el bachiller y el capitán Gonzales

b) Principal: El bachiller; Secundarios: el indio, el capitán Gonzales

c) Principal: El capitán Gonzales; Secundarios: el indio, el bachiller

d) Principal: El indio y el capitán Gonzales; Secundario: el bachiller

1.3. ¿Por qué el capitán Gonzales le asestó un latigazo en la frente al indio?

a) Porque se quedó plácidamente ebrio

b) Porque se quedó plácidamente dormido sobre una vieja de montar

c) Porque se quedó dormido en la habitación del capitán Gonzales

d) Porque no ensilló el caballo que conduciría al Capitán Gonzales al pueblo de Puquio

2. NIVEL INFERENCIAL (8 puntos)

2.1. ¿Qué hubiera sucedido con el capitán Gonzales si el indio no hubiera seguido su camino a Huaraz como guía del bachiller?

a) El capitán Gonzales hubiera regresado a Lima

b) El capitán Gonzales no hubiera vuelto a castigar al indio

c) El capitán Gonzales no hubiera muerto a causa de un empujón del indio

d) El capitán no hubiera perecido a causa de un empujón de los cóndores

2.2. ¿Qué representa el último párrafo del relato?

a) Que nunca es bueno castigar a los vencidos

b) Que es muy bueno castigar a los subyugados

c) A veces no es bueno afrentar con un látigo a los derrotados

d) Ninguna de las anteriores 
2.3. ¿Por qué el bachiller no se fue junto al capitán Gonzales a Huaraz?

a) Porque el indio le dijo que el capitán era un bárbaro

b) Porque el posadero le había aconsejado que no lo hiciera

c) Porque quería comprar aún algunas cosas

d) Porque no tenía provisiones

Lee el siguiente fragmento:

—Tú esperando, taita —murmuró de pronto el guía, y se alejó en un santiamén.

Le aguardé en vano, con la carne erizada. Palpé el revólver en el cinto, estimulando con la voz a la mula indecisa, que, las orejas al viento, oscilantes como veletas, medía el peligro y escuchaba la muerte. Un ruido profundo retembló en la montaña: algo rodaba de la altura. De pronto, a quince metros de mí, pasó un vuelo oblicuo de cóndores, y entonces, distintamente, porque había llegado a un recodo del camino, vi rebotar con estruendo y polvo en la altura inmediata una masa obscura, un hombre, un caballo tal vez, que fue sangrando en las aristas de las peñas hasta teñir el río espumante, allá abajo. Estremecido de horror, esperé mientras las montañas se enviaron cuatro o cinco veces el eco de aquella catarata mortal. Un cono invertido de alas pardas giraba como una tromba sobre los cadáveres.

2.4. A partir del fragmento, ¿Quién causó la muerte del capitán Gonzales?

a) El indio

b) Los cóndores

c) El caballo

d) La mula

e) El bachiller

3. NIVEL CRÍTICO (6 puntos)

3.1. ¿Qué opinión tienes sobre el trato cruel del capitán Gonzales hacia el indio?

3.2. ¿Qué opinión tienes sobre la conducta del indio?

3.3. ¿Qué valores se desprenden del cuento? ¿Por qué?

\begin{tabular}{|c|c|c|c|c|}
\hline \multirow{3}{*}{$\mathrm{N}^{\circ}$} & \multirow{2}{*}{\multicolumn{2}{|c|}{ VALORACIÓN DE LAS ALTERNATIVAS }} & \multirow{3}{*}{$\begin{array}{l}\text { VALOR DE } \\
\text { CADA ÍTEM }\end{array}$} & \multirow{3}{*}{$\begin{array}{l}\text { VALOR TOTAL } \\
\text { DE LA PRUEBA }\end{array}$} \\
\hline & & & & \\
\hline & $\begin{array}{c}\text { ALTERNATIVAS } \\
\end{array}$ & PONDERACIÓN & & \\
\hline $\begin{array}{c}\text { Ítem } \\
1.1\end{array}$ & $\begin{array}{ll}\text { a) } & \text { La identificación de los indios } \\
\text { b) } & \text { El hecho de que el militar le rasgó la frente } \\
\text { al indio de un latigazo } \\
\text { c) } \\
\text { d) El sueño del indio en su aposento } \\
\text { Ninguna de las anteriores }\end{array}$ & $\begin{array}{l}0 \\
2 \\
0 \\
0\end{array}$ & 2 & \\
\hline $\begin{array}{l}\text { Ítem } \\
1.2\end{array}$ & $\begin{array}{l}\text { a) Principal: El indio; Secundarios: el bachiller } \\
\text { y el capitán Gonzales } \\
\text { b) Principal: El bachiller; Secundarios: el } \\
\text { indio, el capitán Gonzales } \\
\text { c) Principal: El capitán Gonzales; } \\
\text { Secundarios: el indio, el bachiller } \\
\text { d) Principal: El indio y el capitán Gonzales; } \\
\text { Secundario: el bachiller }\end{array}$ & $\begin{array}{l}2 \\
0 \\
0 \\
0\end{array}$ & 2 & \\
\hline $\begin{array}{c}\text { Ítem } \\
1.3\end{array}$ & $\begin{array}{l}\text { a) } \quad \text { Porque se quedó plácidamente ebrio } \\
\text { b) } \quad \text { Porque se quedó plácidamente dormido } \\
\text { sobre una vieja de percha de montar } \\
\text { c) } \quad \text { Porque se quedó dormido en la habitación } \\
\text { del capitán Gonzales } \\
\text { d) Porque no ensilló el caballo que conduciría } \\
\text { al Capitán Gonzales al pueblo de Puquio }\end{array}$ & $\begin{array}{l}0 \\
0 \\
2 \\
0 \\
0\end{array}$ & 2 & 20 puntos \\
\hline $\begin{array}{l}\text { Ítem } \\
2.1 .\end{array}$ & $\begin{array}{l}\text { a) } \text { El capitán Gonzales hubiera regresado a } \\
\text { Lima } \\
\text { b) } \quad \text { El capitán Gonzales no hubiera vuelto a } \\
\text { castigar al indio } \\
\text { c) } \quad \text { El capitán Gonzales no hubiera muerto a } \\
\text { causa de un empujón del indio } \\
\text { d) El capitán no hubiera perecido a causa de } \\
\text { un empujón de los cóndores }\end{array}$ & $\begin{array}{l}0 \\
2 \\
0 \\
0 \\
0\end{array}$ & 2 & \\
\hline $\begin{array}{l}\text { Ítem } \\
2.2 .\end{array}$ & $\begin{array}{ll}\begin{array}{l}\text { a) } \\
\text { vencidos }\end{array} & \text { Que nunca es bueno castigar a los } \\
\text { b) } & \text { Que es muy bueno castigar a los } \\
\text { subyugados } & \\
\text { c) } & \text { A veces no es bueno afrentar con } \\
\text { un látigo a los derrotados } \\
\text { d) } & \text { Ninguna de las anteriores } \\
\end{array}$ & $\begin{array}{l}0 \\
2 \\
0 \\
0 \\
0\end{array}$ & 2 & \\
\hline $\begin{array}{c}\text { Ítem } \\
2.3\end{array}$ & $\begin{array}{l}\text { a) Porque el indio le dijo que el capitán era } \\
\text { un bárbaro } \\
\text { b) Porque el posadero le había aconsejado } \\
\text { que no lo hiciera } \\
\text { c) Porque quería comprar aún algunas cosas }\end{array}$ & $\begin{array}{l}2 \\
0 \\
0 \\
0 \\
0\end{array}$ & 2 & \\
\hline
\end{tabular}




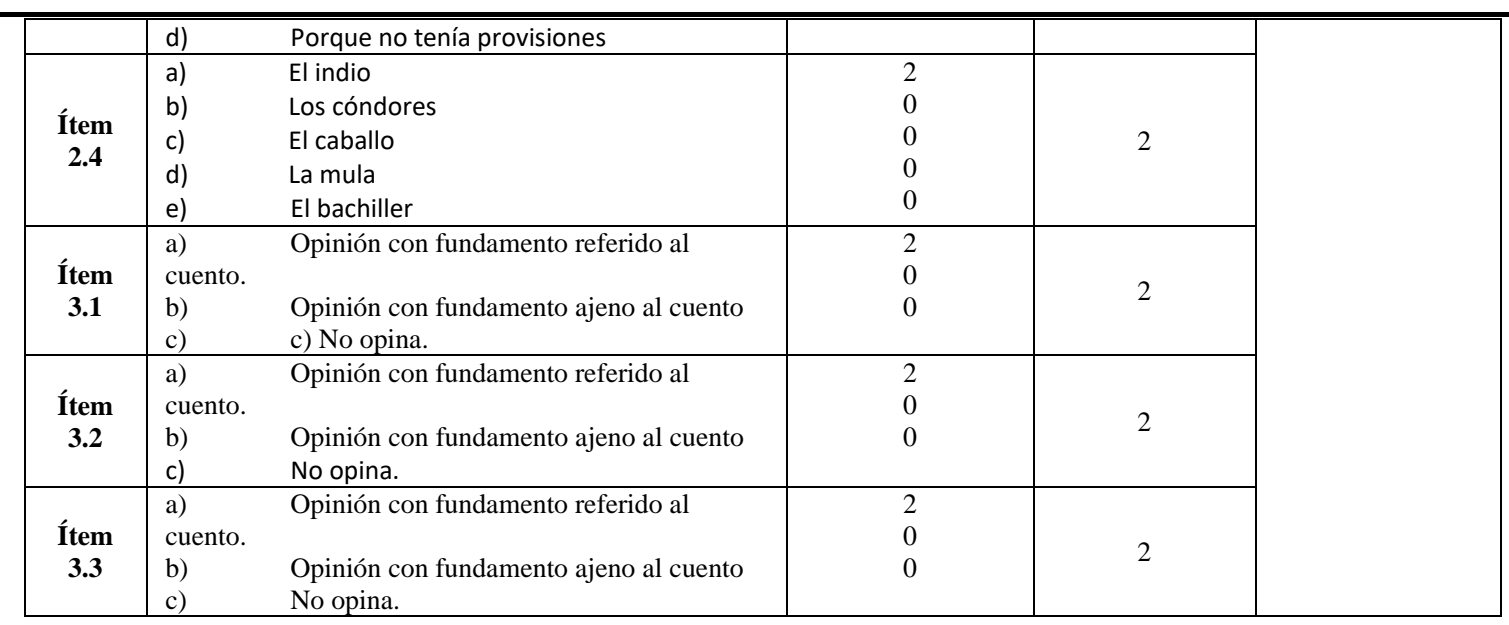

\section{PRUEBA DE SALIDA}

NOMBRES Y APELLIDOS:

\section{GRADO Y SECCIÓN:.}

..FECHA:

\section{LEE ATENTAMENTE EL SIGUIENTE TEXTO:}

Se presentó la lectura:

Paco Yunque (César Vallejo)

\section{RESPONDE ADECUADAMENTE A LAS SIGUIENTES PREGUNTAS:}

\section{NIVEL LITERAL (6 puntos)}

1.1. ¿Cuál es la idea principal del cuento: "Paco Yunque"?

a) La diferencia de las clases sociales

b) La injusticia en los niños

c) Los niños pobres

d) La mala educación

\section{2. ¿Cuáles son los personajes?}

a) Paco Yunque, Humberto Grieve, Paco Fariña, Profesor, Director, Hermanos Zúñiga

b) Paco yunque, Jimenez de la Hoz, Paco Fariña, Humberto Fariña, Timoteo Saavedra.

c) Nicanor Gutierrez, Paco Yunque, Paco Fariña, Humberto Grieve

d) Ninguna de las anteriores

1.3. Cuál es la causa para que Paco yunque asista al colegio:

a) La razón es la de acompañar a Humberto Grieve

b) La razón es la preocupación escolar de su hijo

c) La tristeza de la madre

d) La buena promoción de la educación peruana

\section{NIVEL INFERENCIAL (8 puntos)}

2.1. ¿Qué hubiera sucedido si Paco Yunque hubiera enfrentado a Humberto Grieve?

a) El padre de Grieve hubiera despedido a la madre de Paco.

b) El padre de Grieve hubiera castigado a Paco yunque

c) La madre de Paco Yunque hubiera castigado a Humberto Grieve.

d) Ninguna de las anteriores

2.2. ¿Qué representa el último párrafo del relato?

a) La injusticia en su modalidad más vil.

b) La justicia, ya que Grieve era un niño aplicado.

c) La astucia positiva de Grieve.

d) La soledad de Paco yunque.

2.3. ¿Qué efecto causó en Paco el hecho de supuestamente no haber hecho su tarea?

a) Produjo en el mucha alegría

b) Produjo en el llanto

c) No se inmutó

d) Lo pasó como un suceso inadvertido.

Lee el siguiente fragmento:

El profesor habló en clase sobre los peces y Humberto Grieve decía que los peces podían vivir en su salón porque él tenía mucha plata, todos los niños se ríen y dicen que miente, luego el profesor deja una tarea para después de recreo y mientras escribía Grieve 
jaloneaba a Paco Yunque, Paco Fariña le decía al profesor, cuando el profesor preguntaba todos se quedaban callados porque sabían que Grieve les pegaría a la hora de la salida.

2.4. A partir del fragmento, ¿Por qué Humberto Grieve se comporta de forma injusta?

a) Porque era un niño mimado

b) Porque se había formado en una familia acomodada

c) Porque no quería hacer amistad

d) Porque era travieso por naturaleza

\section{NIVEL CRÍTICO (6 puntos)}

3.1. ¿Qué opinas sobre la actitud del profesor cuando no sancionaba a Humberto Grieve?

3.2. ¿Qué opinas sobre la actitud del autor al escribir el cuento?

3.3. ¿Qué hubieras hecho si hubieras sido Paco Yunque y jugaran al caballito contigo?

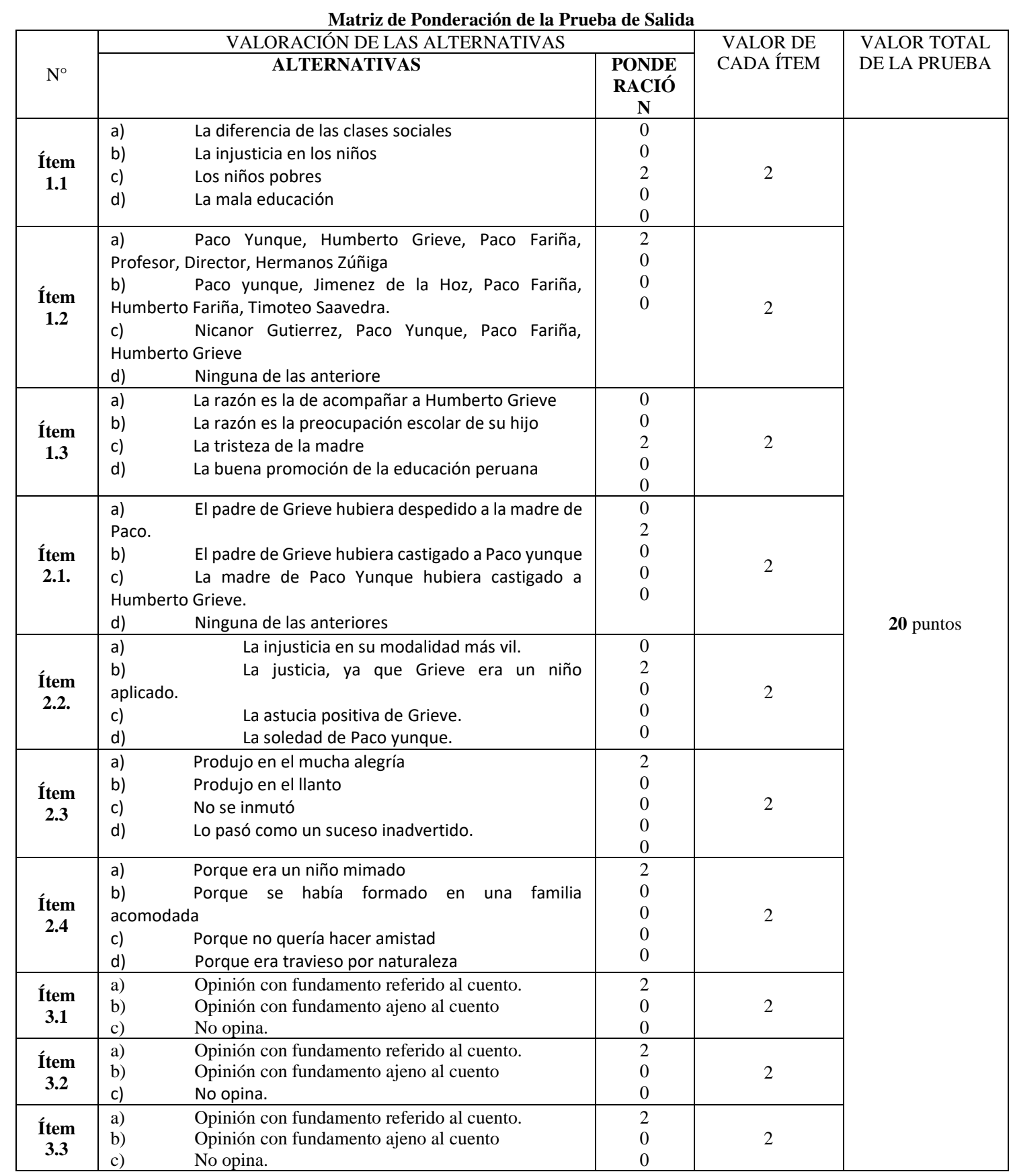

